\title{
Short communication: Influence of retainer configuration and loading direction on the stress distribution of lithium disilicate resin-bonded fixed dental prostheses: 3D finite element analysis
}

Dal Piva, Amanda M O ; Tribst, João P M ; Saavedra, Guilherme S F A ; Souza, Rodrigo O A ; de Melo, Renata M ; Borges, Alexandre L S ; Özcan, Mutlu

\begin{abstract}
The present study elucidates the mechanical performance of different designs of resin-bonded fixed dental prostheses made of lithium disilicate simulating masticatory loads of anterior or canine guidance. A three-dimensional model of maxilla was constructed containing central incisor and canine teeth, with edentulous space of the lateral incisor. Three designs of prosthesis were created: retained in central incisor (1-I), retained in canine (1-C) and fixed in both teeth (2-IC). The computational analysis was performed for load in canine and central incisor separately $\left(100 \mathrm{~N}, 45^{\circ}\right)$. The tensile and shear stresses were calculated for the resin-bonded fixed dental prosthesis, bonding surface of each retainer and cement layer using 3D finite element analysis. The 20 highest stress values were analyzed using two-way ANOVA and post-hoc Tukey test, all with $=5 \%$. The computational analysis showed that 2-retainer resin-bonded fixed dental prosthesis presented the worst prognosis regardless of the mandibular movement. ANOVA showed that Mandibular movement*Retainer interaction influenced on the tensile and shear stresses values $(\mathrm{p}<0.01)$. Higher stresses were observed in the connector region for all groups (13-82.2 MPa; 11-70.2 MPa). In order to reduce the stress concentration in the resin-bonded fixed dental prosthesis and the retainer made of lithium disilicate, the occlusion may serve as the selection criteria of the unitary abutment for better sustainability.
\end{abstract}

DOI: https://doi.org/10.1016/j.jmbbm.2019.103389

Posted at the Zurich Open Repository and Archive, University of Zurich

ZORA URL: https://doi.org/10.5167/uzh-183941

Journal Article

Accepted Version

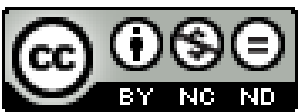

The following work is licensed under a Creative Commons: Attribution-NonCommercial-NoDerivatives 4.0 International (CC BY-NC-ND 4.0) License.

Originally published at:

Dal Piva, Amanda M O; Tribst, João P M; Saavedra, Guilherme S F A; Souza, Rodrigo O A; de Melo, Renata M; Borges, Alexandre L S; Özcan, Mutlu (2019). Short communication: Influence of retainer configuration and loading direction on the stress distribution of lithium disilicate resin-bonded fixed dental prostheses: 3D finite element analysis. Journal of the Mechanical Behavior of Biomedical Materials, 100:103389. 
DOI: https://doi.org/10.1016/j.jmbbm.2019.103389 
Influence of restorative material and cement on the stress distribution of posterior resinbonded fixed dental prostheses: 3D finite element analysis

Short title: Influence of materials and cement on the stress distribution of fixed partial dentures.

João P. M. Tribst, ${ }^{1}$ Amanda M. O. Dal Piva, ${ }^{1, *}$ Renata M. de Melo, ${ }^{2}$ Alexandre L. S. Borges, ${ }^{2}$ Marco Antonio Bottino², Mutlu Özcan ${ }^{3}$

${ }^{1}$ Post-Graduate Program in Restorative Dentistry (Prosthodontic), Department of Dental Materials and Prosthodontics, São Paulo State University (Unesp/SJC), Brazil. Department of Dental Materials Science, Academic Centre for Dentistry Amsterdam (ACTA), Universiteit van Amsterdam and Vrije Universiteit.

Address: Gustav Mahlerlaan \#3004, 1081 LA Amsterdam, Noord-Holland, The Netherlands.

${ }^{2}$ Post-Graduate Program in Restorative Dentistry (Prosthodontic), Department of Dental Materials and Prosthodontics, São Paulo State University (Unesp/SJC), Brazil.

Address: Engenheiro Francisco José Longo Avenue, 777, 12245-000, São José dos Campos/SP, Brazil.

${ }^{3}$ University of Zürich, Dental Materials Unit, Center for Dental and Oral Medicine, Clinic for Fixed and Removable Prosthodontics and Dental Materials Science, Zurich, Switzerland. Address: Rämistrasse 71, 8006 Zurich, Switzerland.

\section{Authors' emails:}

João Paulo Mendes Tribst - joao.tribst@gmail.com; Amanda Maria de Oliveira Dal Piva

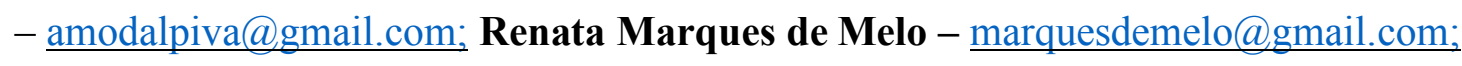
Alexandre Luiz Souto Borges - aleborges@ict.unesp.br; Marco Antonio Bottino mmbottino@uol.com.br; Mutlu Özcan-mutluozcan@hotmail.com.

\section{Corresponding author:}

Amanda Maria de Oliveira Dal Piva, D.D.S, M.S.D., Ph.D. Student

Adress: Gustav Mahlerlaan \#3004, 1081 LA Amsterdam, Noord-Holland, The Netherlands. Mailing adress: amodalpiva@gmail.com (Ms AMO Dal Piva).

Phone: +3168505 1348 Fax: -Email: amodalpiva@gmail.com (Mrs Dal Piva)

Disclosure statement: All authors declare that they have no conflict of interest. 


\section{ABSTRACT}

The goal of this study was to compare the mechanical response of resin-bonded fixed dental prosthesis (RBFDP) made in zirconia, metal, lithium disilicate and composite resin cemented using resin cements with different elastic modulus. For the finite element analysis, a threedimensional model of partial right maxilla was used to create a model with edentulous space in the second premolar and the cavity's preparation on the first pre-molar and first molar to receive a RBFDP. The model was imported to the analysis software in which they were divided into mesh composed by nodes $(371,101)$ and tetrahedral elements $(213,673)$. Each material was considered isotropic, elastic and homogeneous. No-separation contacts were considered between restoration/resin cement and resin cement/tooth. For all other structures the contacts were considered ideal. The model fixation occurred at the base of the bone and an axial load of $300 \mathrm{~N}$ was applied on the pontic occlusal surface. To simulate polymerization shrinkage effects on the cement, the thermal expansion approach was used. The displacement and maximum principal stress (in $\mathrm{MPa}$ ) were selected as failure criteria. The prosthesis made in composite resin showed higher displacement, while in zirconia showed higher stress concentration. Tensile stress between restoration/cement, cement and cement/cavity was directly proportional to the restorative material's elastic modulus. The more rigid cement increases the tensile zones in the cement layer but decreases the stress between prosthesis and cement. The molar cavity showed higher stress concentration between restoration/cement than the preparation in the premolar tooth. The use of composite resin for the manufacturing of RBFDP increases the displacement of the set during the loading. However, it reduces the amount of stress concentration at the adhesive interface in comparison with the other materials.

Keywords: finite element analysis; material properties; dental materials. 


\section{INTRODUCTION}

Resin-bonded fixed dental prosthesis (RBFDP) consist of a minimally-invasive prosthetic treatment (Vallittu, 2004, Alraheam et al., 2019) alternative to rehabilitate edentulous spaces without the need for surgical procedures but allowing the comfort of a fixed prosthesis (Kuijs et al., 2016, Thoma et al., 2017). This restorative modality is used in dentistry in anterior and posterior rehabilitations using adjacent teeth as supports (Rochette, 1973, İzgi et al., 2016, Thoma et al., 2017). The practicality for patient and dentist make this treatment a rehabilitative alternative, because of its minimal-invasiveness, lower costs, and treatment time offer further advantages over traditional fixed dental prosthesis and implant-supported crowns (Thoma et al., 2017). The literature is not concisely regarding the success of this treatment (Rathmann et al., 2017, Thoma et al., 2017, Bömicke et al., 2017). However, a systematic review showed that RBFDP has similar clinical performance than conventional FDP and implant-supported crowns (Alraheam et al., 2019). The preparation of a RBFDP involves numerous clinical and laboratory procedures that, if not performed accurately, may interfere on the result and longevity of the treatment (Rathmann et al., 2017). In addition, numerous materials are available to be used as restorative materials, which may generate doubts about which of these materials would have the best biomechanical performance, since the RBFDP have an adhesive area different from a total crown (Harder et al., 2010, Özcan et al., 2012, Dal Piva et al., 2018, Baran et al., 2018, Bömicke et al., 2018, Alraheam et al., 2019).

The literature reports that posterior RBFDP present a greater chance of mechanical problems compared to fixed prostheses in the anterior area (Thoma et al., 2017). In addition, there are reports of the manufacture of posterior RBFDP in zirconia (Rathmann et al., 2017), metal-ceramics (Bömicke et al., 2018), lithium disilicate (Harder et al., 2010) and composite resin (Özcan et al., 2012). Each materials has the ability to respond mechanically differently to the same applied masticatory force (Dal Piva et al., 2018). However, there are no 
reports on the stress generated in the adhesive interface promoted by different materials. The stress generated at the adhesive interface is of interest to the dentist, since the main failure reported in the literature regarding fixed adhesive prostheses is the detachment and marginal leackage of the adhesive margins (Rathmann et al., 2017, Balasubramaniam et al., 2017). Thus, a restorative material that optimizes the stresses distribution in the adhesive interface during occlusal loading could alleviate the reported clinical problems and promote a higher success rate of posterior RBFDPs.

One of the bioengineering tools able to calculate the stress generated in dental structures is the finite element method (Ausiello et al., 2004, Tribst et al., 2018, Dal Piva et al., 2018, Baran et al., 2018). This method is widely used in the analysis of restorations and complex rehabilitations. This method uses geometries and the structures/materials mechanical properties to verify possible regions of failure in the restoration (Ausiello et al., 2004, Tribst et al., 2018; Baran et al., 2018). This method also allows the isolation of variables of interest with full control of an ideal situation. The finite element method allows the investigation of force by area ratio in different structures. Thus, it allows to determine the influence of the restorative material and the resin cement on the stress generated in the adhesive interface (Ausiello et al., 2004, Dal Piva et al., 2018). This calculation is not possible using another methodology available in the literature. This method has already been used to investigate RBFDP mechanical behavior and to determine the most stressed areas (Heintze et al., 2018, Baran et al., 2019, Waldecker et al., 2019). Therefore, the goal of this study was to compare the mechanical response of RBFDP made in zirconia, metal, lithium disilicate and composite resin cemented using different resin cements. The null hypothesis was that there would be no difference in the result of concentrated stresses for different restorative materials and resin cements. 


\section{MATERIALS AND METHODS}

\subsection{Generation of the Geometric Models}

A 3D model of partial right maxilla from São Paulo State University database (UNESP - ICT São José dos Campos) was selected in stereolithography file and exported to the CAD software Rhinoceros (Rhinoceros version 5.0 SR8, McNeel North America, Seattle, WA, USA). Two sagittal cuts were performed in order to obtain an isolated posterior area. The external surface was redesigned to remove the anatomic variations of the alveolar process. In the lateral view, the bone was divided into cortical and medullar sections and then separated into 2 juxtaposed geometries. The hard lamina was individualized for each tooth (first premolar and first molar) of bone tissue in order to follow the amount of inserted periodontal ligament. For the creation of the geometric model with the teeth macro-structure, a volumetric model is needed. For that, the command "reduce mesh" available with a plugin in CAD software was used with $50 \%$ of relevance, allowing more smooth structure with all normal face oriented in the same direction. The next step was the use of "RhinoResurf", a reverse engineering tool that gives CAD software the ability to reconstruct NURBS surfaces from mesh or point cloud with specified precision. Then a 3D volumetric model of a first molar and first premolar was created based in the surface created by the curve network generated automatically. The pontic was created at the same way but without the root extension. Each solid structure was modeled separately, and the final model contains alveolar bone, cortical bone, periodontal ligament $(0.3$ mm thickness), root dentin and crown for first premolar and first molar. After the model created of sound teeth with edentulous space in the second premolar, the cavity's preparation was performed. For premolar retainer, the cavity was prepared with rounded corners, 6 degree of axial walls, $2 \mathrm{~mm}$ of length, $2 \mathrm{~mm}$ of height and $5 \mathrm{~mm}$ of width. For molar retainer, the cavity was prepared with rounded corners, 6 degree of axial walls, $3 \mathrm{~mm}$ of length, $2 \mathrm{~mm}$ of height and $8 \mathrm{~mm}$ of width. The cement layer was also modeled, with $70 \mu \mathrm{m}$ thickness between the 
internal surfaces of the restoration and bonding surfaces of the teeth. Figure 1 summarizes the modeling used in the mechanical simulation.

\subsection{Finite Element Analysis (FEA)}

The model was imported through STEP format for the analysis software (ANSYS 17.2, ANSYS Inc., Houston, TX, USA), in which they were divided into mesh composed by nodes $(371,101)$ and tetrahedral elements $(213,673)$ (Fig. 2). The aspect ratio of mesh metrics presented average of 1.74 with standard deviation of 0.4 . Mechanical properties of each material/structure used were inserted into the analysis software and each material was considered isotropic, elastic and homogeneous. No-separation contacts were considered between restoration/resin cement and resin cement/tooth, in which the target and contact surfaces are tied for the remainder of the analysis although sliding is permitted (Tribst et al., 2018). Between all other structures the contacts were considered ideal. For boundary conditions, the model fixation occurred at the base of the bone and an axial load of $300 \mathrm{~N}$ (Tribst et al., 2018) was applied to the occlusal landmarks on the pontic (Peixoto et al., 2014) (Fig. 2). The $300 \mathrm{~N}$ load was determined based on the average of unilateral bite force in premolar region (210 - 420), being 70\% inferior than molar region (Bakke, 2006). A mesh convergence test $(10 \%)$ was performed to guarantee that the mesh would not interfere in the results. To simulate polymerization shrinkage effects of adhesive layers, the thermal expansion approach was used. Assuming a one-degree drop in temperature, the adhesive layer would shrink and generate stress at the tooth-restoration interface (Ausiello et al., 2004, Tribst et al., 2018, Correia et al., 2018). The displacement and maximum principal stress (in $\mathrm{MPa}$ ) were selected as failure criteria. In addition, the stress peak in each structure of the adhesive interface according to the retainer, restorative material and resin cement were obtained. For that, all stress numerical data in each surface were exported to an excel file, where they were organized from the maximum to minimum to determine the highest value. 


\section{RESULTS}

Results of prosthesis displacement (in mm) and maximum principal stress ( $\mathrm{MPa}$ ) for the restoration, cement layer and dental structure were obtained. Regarding the prosthesis, the data was summarized through colorimetric graphs for displacement (Fig. 2) and tensile stress (Fig. 3). Regardless the cement, the prosthesis made in composite resin showed higher displacement, while in zirconia showed higher stress concentration (Fig. 4). Tensile stress between restoration/cement, cement and cement/cavity was directly proportional to the restorative material's elastic modulus. The more rigid cement increases the tensile zones in the cement layer but decreases the stress between prosthesis and cement. In addition, higher stress concentration was observed in the connector region. The adhesive interface was assumed by the restoration intaglio surface, cement layer and external surface of the cavity. The maximum principal stress criteria was recorded for these 3 structures separately, for each retainer. The maximum displacement and higher stress peaks were summarized in the table 1 for quantitative comparison in $\mathrm{MPa}$ and plotted in graph of overlapping bar for the visualization of the stress amount in the interface. Table 2 shows the results of displacement for the prostheses and results of stress in each structure of the adhesive interface according to the retainer, restorative material and resin cement. Superimposed bar graph for the stresses generated in each geometry of the adhesive interface according to the evaluated resin cement and retainer is presented in Figure 5.

\section{DISCUSSION}


The results of the present study showed that the elastic modulus of restorative material and the resin cement can influence the stress concentration at the adhesive interface. Thus, the hypothesis was rejected. In this theoretical study, four restorative materials were simulated for the manufacturing of a posterior RBFDP. For each material, two different calculations were performed based in the resin cement used.

The use of adhesive prostheses is commonly applied in dentistry as an option against more invasive treatments (Kuijs et al., 2016, Thoma et al., 2017). With the advent of increasingly reliable resin cements, the cementation of extensive restorations and fixed prostheses is increasingly easily performed and indicated to achieve success rates over five years (İzgi et al., 2016, Thoma et al., 2017, Alraheam et al., 2019) with similar performance to the conventional fixed dental prosthesis or implant-supported crowns (Alraheam et al., 2019). The association of adhesive cements with a minimally invasive dentistry makes extensive preparation on the abutment teeth to support the fixed prosthesis to be performed less and less. Thus, the present study simulated a minimum preparation approach, whose each adjacent teeth to the edentulous space received only one class II preparation. According to the literature, class II restored teeth with indirect restorations present the highest stress peaks in the adhesive interface region (Ausiello et al., 2017). However, when this cavity is used to support a posterior RBFDP, the tensile stress concentration occurs in the conection with the pontic (Baran et al., 2018, Heintze et al., 2018, Waldecker et al., 2019). In this way, the results herein corroborate with previous papers when demonstrates that the connector region is the most stressed area for RBFDP and with paper with conventional Class II restorations exhibiting stress concentration in the adhesive interface.

The problems reported in resin bonded prostheses in the posterior area are still more frequent than the problems found in the anterior area (Thoma et al., 2017). In this way, being considered as an approach that needs more investigations. Although this conservative approach 
is based on principles of tooth structure preservation and adherence, some clinical failures are reported, compromising treatment longevity due to marginal leackage and restorations debonding (Bömicke et al., 2017). One of the factors that can be controlled by the clinician is the selection of restorative materials that will be used in the patients rehabilitation (Harder et al., 2010; Özcan et al., 2012; Dal Piva et al., 2018; Baran et al., 2018; Bömicke et al., 2018; Alraheam et al., 2019). Among them, the restorative material and the bonding agent to be used for its fixation. Based on the results herein, both materials can modify the mechanical response generated at the adhesive interface with the same applied load.

The adhesive interface was simulated containing three distinct but juxtaposed structures: the intaglio surface of restorative material, resin cement and cavity external surface (Fabianelli et al., 2005). In each structure there is a different stress concentration depending on the elastic modulus of each restorative material (Ausiello et al., 2004, Dal Piva et al., 2018). Thus, the literature presents situations of adhesive failure between restoration / cement, cement / tooth and even cohesive failure of the cement itself (Tribst et al., 2018). Each possible failures that occur at the interface seems to be directly related to the different stress concentrations in these structures (Dal Piva et al., 2018), which has not been investigated yet in RBFDPs. Regarding the RBFDP structure, the high stress concentration was observed in the connector area corroborating a previous reported (Baran et al., 2018). These stressed areas increased with the increase of restorative material elastic modulus. For a total crown, for example, different restorative materials may present different risks of adhesive or cohesive failure based on the tensile values generated in the cement layer. Also, the more rigid the crown the higher the failure risk in the cement layer (Dal Piva et al., 2018). Likewise, the present study found that more rigid fixed prostheses, such as zirconia, present a higher stress concentration in the adhesive interface for both abutments. This finding proposes a justification for the prospective 
clinical study of Rathmann et al. (2017), whose survival rate of posterior fixed prostheses in zirconia in 10 years was $12 \%$ and the success rate was $0 \%$.

It is possible to observe that there is a directly proportional tendency between the elastic modulus of the restorative material and the stress concentration between restoration/cement and cement/tooth. However, inversely proportional to the stress concentration inside the resin cement. Observing the adhesive interface as a set, there is a decrease of stress in the interface when using flexible materials as composite resin. The lower the material elastic modulus the greater the prosthesis displacement. Thus, damping the masticatory load that would stress the surface of the restoration and the cavity, but damaging more easily the resinous cement layer. This means that the use of less rigid restorative materials is likely to be more susceptible to improved performance with the use of resin cements whose tensile strength is high, while high resilient materials rely more on resin cements with a higher adhesive strength.

The stress accumulated in the resin cement can be reduced if a less rigid cement is used. However, it would generate more stress concentration in the restoration intaglio surface and in the external surface of the dental element. It should be noted that the simulated cements have different adhesive properties and chemical composition. But, herein, only their mechanical properties were considered for the simulation due to the method limitations.

Harder et al. (2010) evaluated fixed prostheses in lithium disilicate in 42 patients whose prosthesis design was similar to the one simulated in the present study. As simulated herein, the authors cemented the prostheses with Variolink II and found that survival rate for inlay-retained fixed dental prostheses was $57 \%$ after 5 years and $38 \%$ after 8 years. The authors observed a greater number of fractures than of debonding as clinical failures, mainly in the molar region. The authors associated the results with higher levels of masticatory stress in the first molar region. The present study corroborates the predominance of higher values of stress in the molar 
(Fig. 5), but because the load was not applied directly on it, this result probably occurs due to the size of the cavity.

Regardless the restorative material and the resin cement, another result that should be observed is that the molar tooth had higher stress values at the interface (in the resin cement and in the intaglio surface of the restoration) (Fig. 5). Probably the stress generated in the molar tooth cavity is due to the higher $\mathrm{C}$ factor in these cavities (Correia et al., 2018), since as the resin cement will contract as a whole, the higher the tensile stress generated in larger areas. In contrast, the pre-molar presents higher accumulated stress between tooth/cement with little difference as a function of the material or the cement, showing that the cavity geometry was more important for smaller volumes of resin cement than the other evaluated factors. Future studies should be conducted to evaluate the influence of the geometry of the cavity preparation on the stress concentration in the adhesive interface of fixed prostheses.

Bömicke et al., 2018, tested the load-bearing capacity of different RBFDPs in posterior region, whose pontic was the lower first molar. The authors defined that the use of a zirconia prosthesis is less conductive to mechanical failure than metal-ceramic prostheses and found that more extensive preparation to support the fixed prosthesis allows obtaining higher fracture loading values. Thus, the present study did not aim to analyze the stress to fracture the RBFDPs but its effect on debonding, which is reported as a the most common failure (Balasubramaniam, 2017). Other variables reported in the literature able to affect the success of a RBFDP were not simulated and should be taken into account, such as the experience of the dentist who manufacture the prosthesis (Tanoue, 2016), point of loading, loading and occlusal morphogology (Özcan et al., 2012).

\section{CONCLUSIONS}


Based in this study, the following can be concluded:

-The use of composite resin for the manufacturing of resin-bonded fixed dental prosthesis increases the displacement of the prosthesis during the loading. However, it reduces the amount of stress concentration at the adhesive interface in comparison with metal, lithium dissilicate and zirconia;

\section{ACKNOWLEDGEMENTS}

None. 


\section{References}

1. Alraheam IA, Ngoc CN, Wiesen CA, Donovan TE. Five-year success rate of resin-bonded fixed partial dentures: A systematic review. J Esthet Restor Dent 2019; 31:40-50.

2. Ausiello P, Ciaramella S, Garcia-Godoy F, Gloria A, Lanzotti A, Maietta S, Martorelli M. The effects of cavity-margin-angles and bolus stiffness on the mechanical behavior of indirect resin composite class II restorations. Dent Mater. 2017 Jan;33(1):e39-e47.

3. Ausiello P, Rengo S, Davidson CL, Watts DC. Stress distributions in adhesively cemented ceramic and resin-composite Class II inlay restorations: a 3D-FEA study. Dent Mater 2004; 20: $862-872$.

4. Bakke M. Bite Force and Occlusion. Semin in Orthod 2006, 12: 120-126

5. Balasubramaniam GR. Predictability of resin bonded bridges - a systematic review. Bra Dent J 2017; 222: 849-858.

6. Baran I, Arslan M, Gungor H. Effect of different framework materials of resin-bonded bridges on load to fracture values and stress distribution. Niger J Clin Pract 2018; 21: 15851589.

7. Bömicke W, Karl J, Rammelsberg P. Minimally invasive prosthetic restoration of posterior tooth loss with resin-bonded, wing-retained, and inlay-retained fixed dental prostheses fabricated from monolithic zirconia: A clinical report of two patients. J Prosthet Dent 2017; 117: 459-462.

8. Bömicke W, Waldecker M, Krisam J, Rammelsberg P, Rues S. In vitro comparison of the load-bearing capacity of ceramic and metal-ceramic resin-bonded fixed dental prostheses in the posterior region. J Prosthet Dent 2018; 119: 89-96.

9. Çaglar A, Bal BT, Karakoca S, Aydın C, Yılmaz H, Sarısoy S. Three-dimensional finite element analysis of titanium and yttrium-stabilized zirconium dioxide abutments and implants Int J Oral Maxillofac Implants 2011; 26: 961-969. 
10. Correia AMO, Tribst JPM, Matos FS, Platt JA, Caneppele TMF, Borges ALS.Polymerization shrinkage stresses in different restorative techniques for non-carious cervical lesions. J Dent 2018; 76: 68-74.

11. Dal Piva AMO, Tribst JPM, Borges ALS, Souza ROAE, Bottino MA. CAD-FEA modeling and analysis of different full crown monolithic restorations. Dent Mater 2018; 34: 13421350.

12. Fabianelli A, Goracci C, Bertelli E, Monticelli F, Grandini S, Ferrari M. In vitro evaluation of wall-to-wall adaptation of a self-adhesive resin cement used for luting gold and ceramic inlays. J Adhes Dent 2005; 7: 33-40.

13. Güngör M, Küçük M, Dündar M, Karaoğlu C, Artunç C. Effect of temperature and stress distribution on all-ceramic restorations by using a three-dimensional finite element analysis. J Oral Rehabil 2004; 31: 172-178.

14. Harder S, Wolfart S, Eschbach S, Kern M. Eight-year outcome of posterior inlay-retained all-ceramic fixed dental prostheses. J Dent 2010; 38: 875-881.

15. Heintze SD, Monreal D, Reinhardt M, Eser A, Peschke A, Reinshagen J, Rousson V. Fatigue resistance of all-ceramic fixed partial dentures - Fatigue tests and finite element analysis. Dent Mater 2018; 34: 494-507.

16. İzgi AD, Şebnem E, Kale E. Retrospective study on the 7.5-year survival of resin-bonded dental prostheses in single missing second premolar cases. J Indian Prosthodont Soc 2016; 16: $26-29$

17. Kuijs R, van Dalen A, Roeters J, Wismeijer D. The resin-bonded fixed partial denture as the first treatment consideration to replace a missing tooth. Int J Prosthodont 2016; 29: 337-339.

18. Ma L, Guess PC, Zhang Y. Load-bearing properties of minimal-invasive monolithic lithium disilicate and zirconia occlusal onlays: finite element and theoretical analyses. Dent Mater 2013; 29: 742-751. 
19. Monteiro JB, Dal Piva AMO, Tribst JPM, Borges ALS, Tango RN. The effect of resection angle on stress distribution after root-end surgery. Iran Endod J 2018; 13: 188-194.

20. Ozcan M, Breuklander M, Salihoglu-Yener E. Fracture resistance of direct inlay-retained adhesive bridges: effect of pontic material and occlusal morphology. Dent Mater J 2012; 31:514-522.

21. Peixoto AP, dos Santos Pinto A, Garib DG, Gonçalves JR. Three-dimensional dental arch changes of patients submitted to orthodontic-surgical treatment for correction of Class II malocclusion. Dental Press J Orthod. 2014 Jul-Aug;19(4):71-9.

22. Rathmann F, Bömicke W, Rammelsberg P, Ohlmann B. Veneered zirconia inlay-retained fixed dental prostheses: 10-Year results from a prospective clinical study. J Dent 2017; 64: $68-72$.

23. Rochette AL. Attachment of a splint to enamel of lower anterior teeth. J Prosthet Dent 1973; 304: 418-423.

24. Srirekha A, Bashetty K. A comparative analysis of restorative materials used in abfraction lesions in tooth with and without occlusal restoration: three-dimensional finite element analysis. J Conserv Dent 2013; 16: 157-161.

25. Tanoue N. Longevity of resin-bonded fixed partial dental prostheses made with metal alloys. Clin Oral Investig 2016; 20:1329-1336.

26. Thoma DS, Sailer I, Ioannidis A, Zwahlen M, Makarov N, Pjetursson BE. A systematic review of the survival and complication rates of resin-bonded fixed dental prostheses after a mean observation period of at least 5 years. Clin Oral Implants Res 2017; 28:1421-1432.

27. Toparli M. Stress analysis in a post-restored tooth utilizing the finite element method. J Oral Rehabil 2003; 30: 470-476. 
28. Tribst J, Anami LC, Özcan M, Bottino MA, Melo RM, Saavedra G. Self-etching primers vs acid conditioning: impact on bond strength between ceramics and resin cement. Oper Dent 2018; 43: 372-379.

29. Tribst JPM, Dal Piva AMO, Madruga CFL, Valera MC, Borges ALS, Bresciani E, de Melo RM. Endocrown restorations: Influence of dental remnant and restorative material on stress distribution. Dent Mater 2018; 34: 1466-1473.

30. Vallittu PK. Survival rates of resin-bonded, glass fiber-reinforced composite fixed partial dentures with a mean follow-up of 42 months: a pilot study. J Prosthet Dent. 2004 $\operatorname{Mar} ; 91(3): 241-6$.

31. van Dalen A, Feilzer AJ, Kleverlaan CJ. In vitro exploration and finite element analysis of failure mechanisms of resin-bonded fixed partial dentures. J Prosthodont 2008; 17: 555-561.

32. Versluis A, Tantbirojn D, Pintado MR, DeLong R, Douglas WH. Residual shrinkage stress distributions in molars after composite restoration. Dent Mater 2004; 20: 554-564.

33. Waldecker M, Rues S, Rammelsberg P, Bömicke W. Validation of in-vitro tests of zirconiaceramic inlay-retained fixed partial dentures: A finite element analysis. Dent Mater 2019; 35: e53-e62. 


\section{LEGENDS}

Table I. Mechanical properties of the materials/structures used in this study.

Table II. Results of displacement for the prostheses and results of stress in each structure of the adhesive interface according to the retainer, restorative material and resin cement.

Figure 1(A-B) Schematic illustration of three-dimensional modeling. (A) Three-dimensional geometry of a posterior resin-bonded fixed dental prosthesis (RBFDP) with inlay retainers (in blue), cement layer (in green) and teeth preparation to receive the prosthesis. (B) Cemented RBFDP or final three-dimensional model. The final model contains cortical bone, cancellous bone, periodontal ligament, prepared teeth with enamel and dentin, cement layer and the resinbonded fixed partial denture.

Figure 2(A-B). Boundary condition. (A) Load application on the occlusal surface of the pontic. (B) Mesh generation with tetrahedral elements.

Figure 3. Displacement results $(\mathrm{mm})$ in the prosthesis according to the restorative material and resin cement.

Figure 4. Maximum principal stress results $(\mathrm{MPa})$ in the prosthesis according to the restorative material and resin cement.

Figure 5. Superimposed bar graph for the stresses generated in each geometry of the adhesive interface (stress between restoration/cement, stress at the cement and stress between cavity/cement) according to the evaluated resin cement and retainer. 
able 1. Mechanical properties of the materials/structures used in this study.

Material/Structure

Zirconia

Titanium

Lithium Disilicate

Composite Resin

Resin cement Panavia F2.0

(Kuraray Medical, Okayama, Japan)

Resin cement Variolink II Ivoclar

8.3

200

0.31

0.33

0.25

0.28

Srirekha, Bashetty, 2013

(Vivadent, Schaan, Liechtenstein)

\begin{tabular}{cccc}
\hline Dentin & 18.6 & 0.32 & Monteiro et al., 2018 \\
\hline Enamel & 84.1 & 0.33 & Versluis et al., 2004 \\
\hline Cortical bone & 13.7 & 0.30 & Monteiro et al., 2018 \\
\hline Cancellous bone & 1.37 & 0.30 & Monteiro et al., 2018 \\
\hline Periodontal Ligament & 0.069 & 0.45 & Monteiro et al., 2018
\end{tabular}

\section{Reference}

Çaglar et al., 2011

Toparli, 2003

Ma et al., 2013

$11 \quad 0.28 \quad$ Srirekha, Bashetty, 2013

$12 \quad 0.33 \quad$ van Dalen et al., 2008

$0.24 \quad$ Güngör et al., 2004 
able 2. Results of displacement for the prostheses and results of stress in each structure of the adhesive interface according o the retainer, restorative material and resin cement.

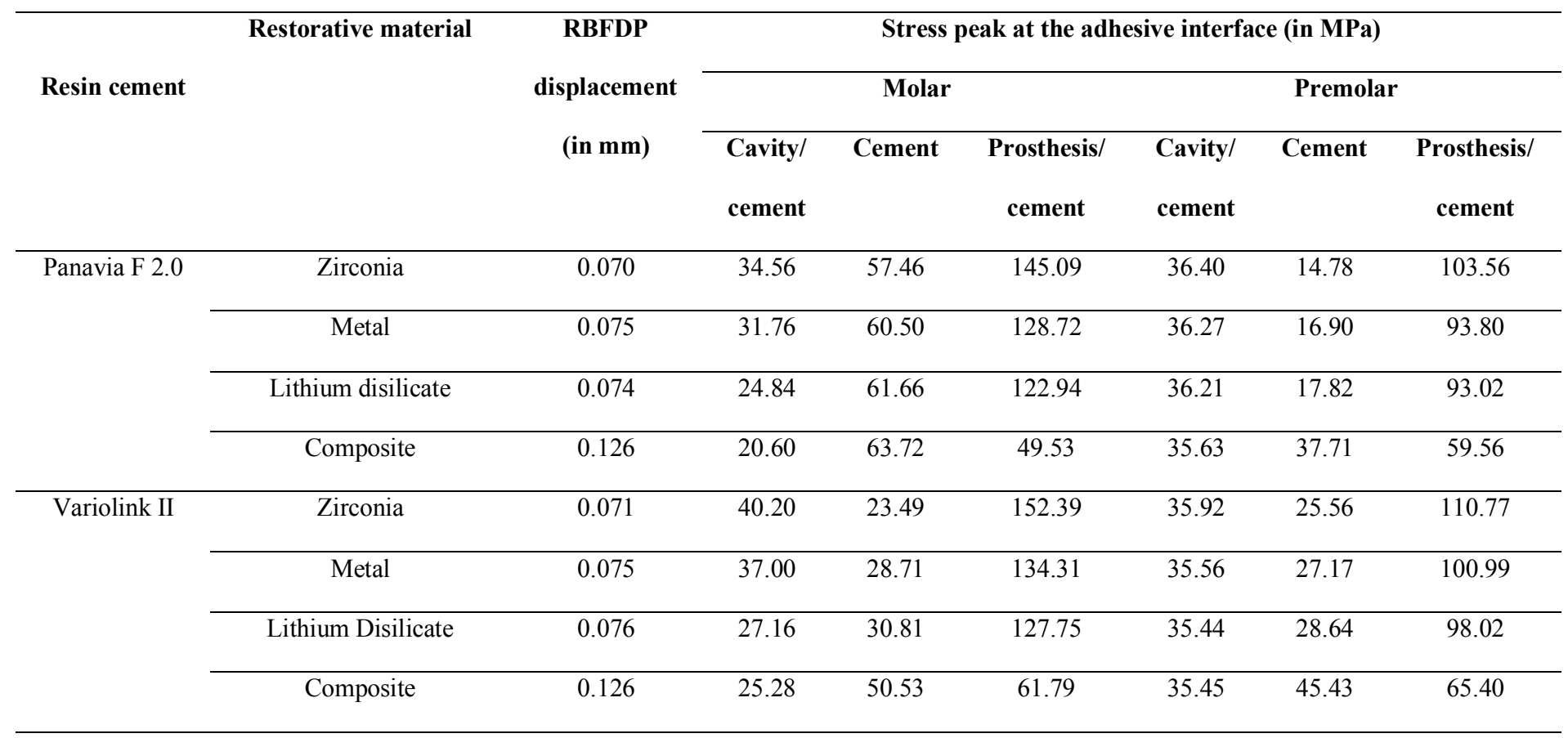



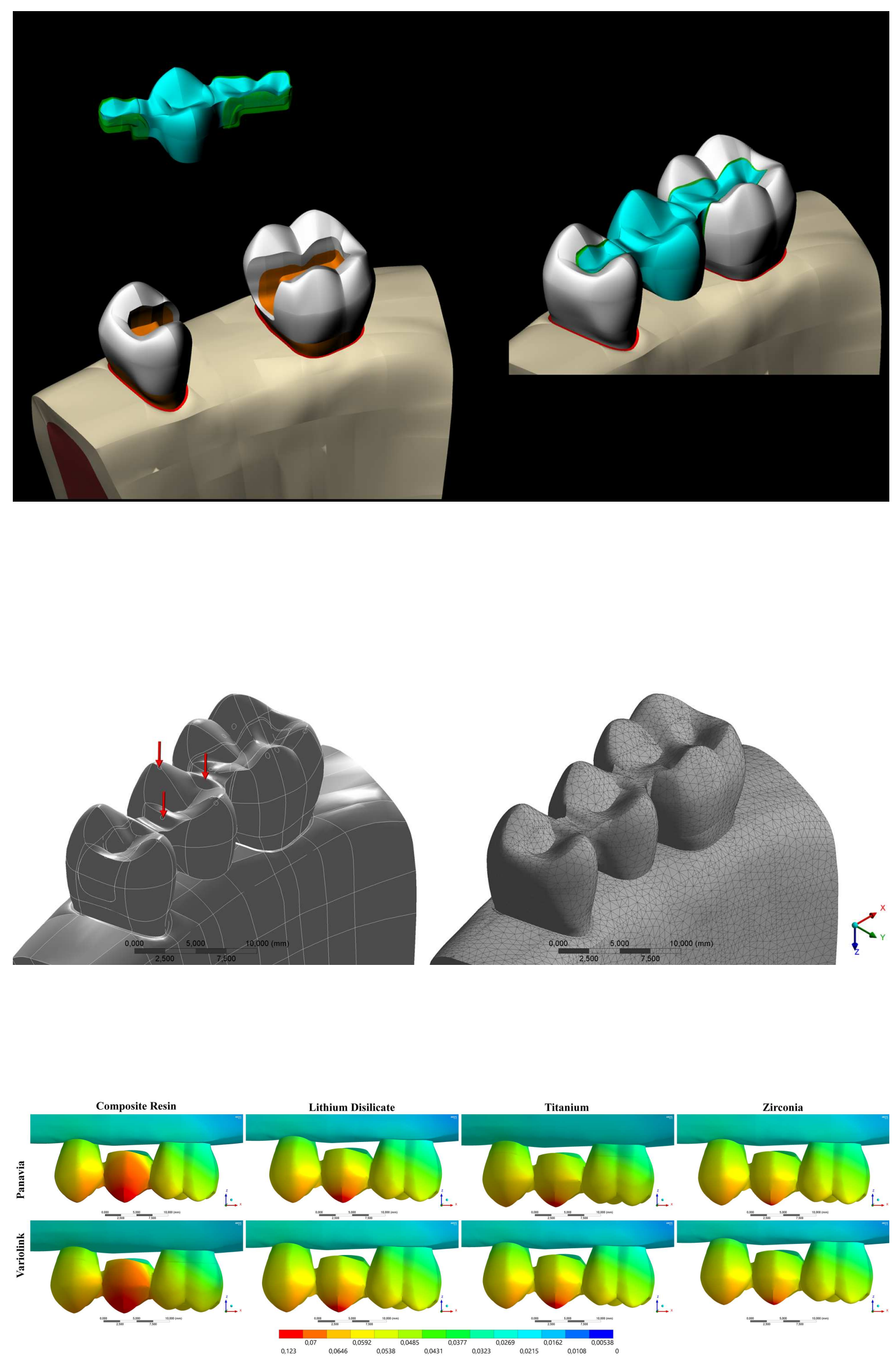


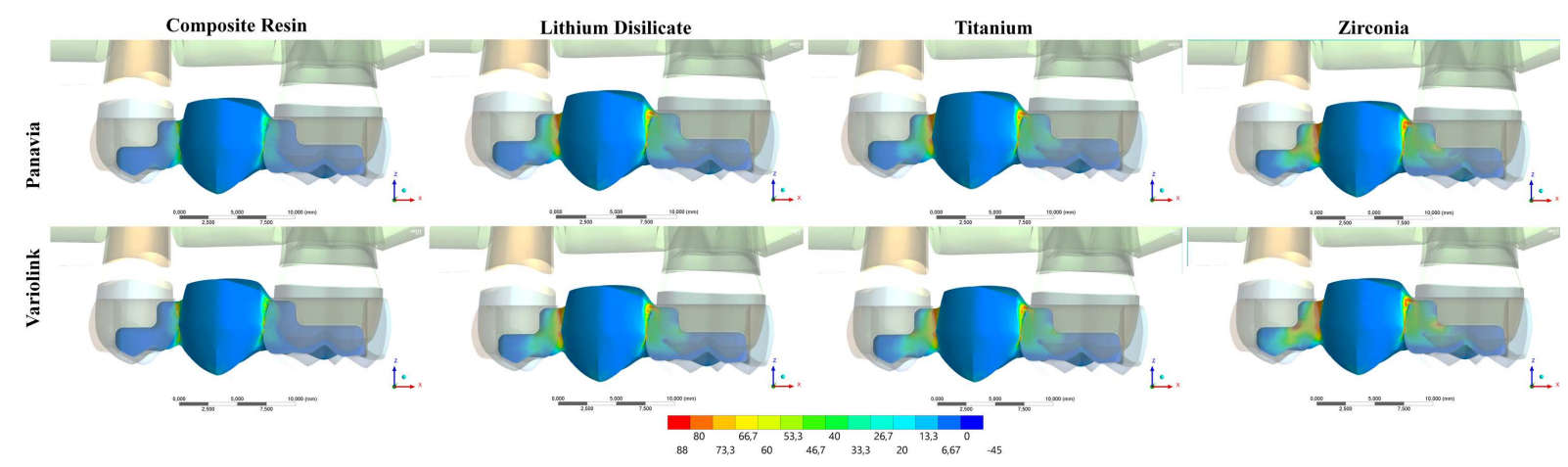

